\title{
An Early Childhood Care and Development Policy of Bhutan
}

\author{
Kinzang Dem* \\ Ministry of Education, Royal Government of Bhutan
}

\begin{abstract}
An early childhood care and education development as the essential foundation for any education system is given priority in Bhutan lately. This was significant from the drafting of Bhutan's Early Childhood Care and Development policy in 2008. It typically covers key strategies and specific modes of specific implementations befitting Bhutanese children. Now, due to progressively increasing social change in modern society such an increasing rate of nuclear family households, local unemployment, and rapid urbanization. And growing need of the children and in preparing the children for the $21^{\text {st }}$ century, an early childhood and development programs are gaining more attention than before in Bhutan. With a visible change, visible gaps in policy texts and implementations have been noticed by the people in the fields. The change is a result of the global networks' influences and globalization thus, globalization is considered an influential factor in policy frameworks of under developing countries. The notable difference in care and early learning in between the urban independent centers and rural centers have led to study policy interactions at various levels. For this independent study, the policy trajectory method will carefully analyze its policy text production, influence, and potential impact of global policies to local policies.
\end{abstract}

Keywords: early childhood care and development policy, globalization, trajectory method, equity, and equality

\section{Introduction}

Bhutan represents a land-locked country between two giant countries, to its north lies China and to its south India. Its high mountains stretch along the Eastern Himalayans. Having the privilege of working at a school for many years and policy carriers for early childhood care centres from 2011 till date, I get opportunities to interact with both rural and urban parents. It is also one of the least populated countries that inclines to India for trade. With a continual influx of prospective migrant and immigrant workers in South Asia, a visible change in social culture, economics and politics in Bhutan is also taking place. With the introduction of television and the Internet in 1999, Bhutan longer befalls an isolated country. Change has been inevitable which is primarily due to globalization cited as the key to defining our culture, politics and economy. It is clear education is the mainstay of all economies. The country seeks to make it vibrant in terms of economy, culture, and politics through investment in education and its policies. Consequently, it drafted ECCD policy in 2008. Through its guidelines and strategies, Bhutan aspires to prepare future citizens much stronger and competent adults capable of meeting the scope of the $21^{\text {st }}$-century skills.

Having the privilege of working at a school for many years and policy carriers for early childhood care centers from 2011 till date, I get opportunities to interact with both rural and urban parents. During the field visits, I also listen eagerly to the valuable perspectives of rural people regarding early childhood policy and practices. Besides, through my observations, a visible difference in infrastructure, learning environment, students' exposure, and facilitators' competency was noticed in different settings. To such a degree, an ample scope in carefully analyzing the ECCD policy of Bhutan is evident as no one has done till today.

The gaps like responsibility, management practices, standards, resource allocation, quality and equity, caregiver quality and learning outcomes are found. Promptly adopting the trajectory policy to carefully analyze the ECCD policy of Bhutan could aid in searching for possible solutions to the present problems. 
Method

\section{Policy Trajectory Approach}

Policy in a change process of education underpins the rules necessary for the effective engagement of people in the communities. Education policy positively reflects the underlying values undoubtedly contributing to holistic health and intellectual growth in modern education systems. Policy is carefully defined "Text and action, words and deeds, what is enacted as well as intended" (Ball, 1994, p. 11). Policy enactment frequently depends upon individuals or communities to negotiate actively to shift gears towards modern practices following the policy documents. However, the fundamental reality of social inequality, the inappropriateness of policy at local contexts and apparent lack of valuable resources intellectually and economically challenge the educational policy execution. This gap between the intention of policies and their consequences recognizes (Ball, 1994). Carefully tracing the local practices and affects in local settings could positively identify the unintended consequences of policies (Braun et al., 2011.).

Rawl's (1921) theory on social justice highlights the significance of providing equitable rights, access and ample opportunity so that the least advantaged groups are benefitted. So, policies are naturally supposed to adequately protect the social and economic aspects of the local people. Thus, the discourse dimensions of independent policies enacted at local levels could be better examined (Ball, 1994; Rizvi \& Lingard, 2010; Vidovich, 2013). The urgent need for the significant protection of the marginal group of children from rural background needs to be addressed. And they are equally aware of their children's right and accessibility to education. The trajectory approach provides the power of recognizing global policies. A significant influence of it on local policy documents and discourses in adopting policies could be examined. Further, power choice or flexibility, roles of stakeholders while policies are in action, enactment issues, and the policy's reliability and relevancy could be investigated. Through this study, one could draw some significant themes of social justice, liability, quality, and equity.

It is significant to examine the point of policy influence, its impact and change in policy adoptions impact at varying levels. The three comparable levels of mutual interactions like macro, meso and micro levels would be studied to properly understand different policy point of possible influence. The macro-level is examining interactions between nations or comparisons across nations at the widest level. Meso- level is studying possible experiences of specific groups and meaningful interaction between groups. Micro-level is exploring how people balance their roles and identities their roles due to various interaction scales (Blackstone, 2015). This independent investigation of interactions, influence, and potential impact at diverse levels could graciously assist in naturally understanding the relevancy. It would additionally provide an ample scope for possible innovation, altering practices and contextualizing ECCD practices into more authentic and manageable execution processes. Thus, intended to contribute an information about policy for understanding quality and social equity.

\section{Result}

\section{Influence from Global to Local Context}

Globalization is contested to a great extent (Rizvi \& Lingard, 2010). It is a concept used for describing responses to desirable changes. It affects our ideas of interpreting changes and possibilities of our future being connected more than ever. A globalized world is equally described as a period of intense compression of time and space producing 'disorientation' and 'disruption' impacting political and economic practices, the class power balance, cultural and social life (Rizvi \& Lingard, 2010). Therefore, a government needs to recognize the impact of globalization on social space and how best they could provide opportunities for the thinner sections of society to enjoy the same benefits. 
Through the educational discourses in policies, the international organizations promote the neoliberal images of education and are adopted voluntarily by the national systems that benefit from grants and aids. Rizvi \& Lingard (2010) claim that globalization manifest in possible ways in diversified economies, cultures and politics. But the discourses remain the mainstream being identified by the market advantage. Because of this image, everybody is competing for jobs and business. Such a neoliberalism image creates polarization of rich and poor.

The rural background of Bhutanese consists of mostly from the low-income groups. Close to $93.8 \%$ of population of Bhutan are from the agriculture background (census report, 1998). They consist of the key illiterate section of the society. The inequality in the society could be correctly understood from the poor livelihood of the people in the rural areas. Lowly economic status and social background seem to be the reasons giving rise to inequality in the society which OECD (2015) confirms to impact education. Like any other country, Bhutan too aspires to improve the lives of its people by establishing a secure foundation for initial education and care. As a consequence, the government established a reasonable ground for early learning care and support mechanisms. Providing quality and equity in early childcare education opportunities to disadvantaged children is one way of promoting conditions to improve the social lives of the children. Cobbold's (2011) view on equity reveals the students are diverse in their needs to achieve any particular level of achievement. It is also pointing to the disadvantaged social environment or special education needs for a low level of achievement by students at a given input level. Therefore, he advises that equity in education may look for unequal resources and support systems applied to diverse students to obtain the anticipated outcome. In this regards, the rural ECCD centers be given more resources and unequal support so that their socially disadvantaged environment could be lifted.

Globalization has prepared the world a global village where global networks are taking place at significant stakes so the global economy depends largely on global networks. Organization for Economic Co-operation and Development (OECD), World Bank, Save the Children and United Nations International Children's Emergency Fund (UNICEF) as supra-national organizations fulfil their roles in promoting the principles global network and its benefits. Such networks are influencing Bhutanese views about the world and is going to affect it's generations through international education directives and guides in the form of global and national policies. The circulation and comparison of educational policies taking place at numerous bases across the national boundaries an evidence for the global influences (Rizvi \& Lingard, 2010). The borrowing of policies is the result of exploring the social, political and economic contexts that influence global education policy and policymaking. And applying guidance in various contexts. Such reforms or practices could lead to inadequate execution of policies. Being aware of this fact, Bhutanese policymakers could focus on the practicality, relevancy, choices, and impact of adopting such policies. Levin (2010) argues that attention must be directed to reliable research evidence for any strong education reforms.

The OECD's (2015) on Early Childhood Education and Care (ECEC), quality childhood care and education pointed out numbers of benefits. Some of them are better well-being of children and their improvement in the learning outcome; poverty reduction and increased reasonable outcome; increased social mobility amongst intergeneration; significant participation of female labor market and gender equality; better economic development; and social participation for broader society. Such tones explicitly apply OECD's convention to trying to achieve its market philosophy by attempting to persuade developing countries in adopting such policies. It could be viewed as making policy decisions for developing countries, which could lead to dangers of exposing to external dictates and their inquiry (Rizvi \& Lingard, 2010). In this way, decreasing the policy independence of a country which needed different interventions to suit its contexts, priorities, and needs.

OECD as policy player initiated reviews of national early childhood care beginning from1996 with twenty countries like Australia, Austria, Belgium (two communities), Canada, Czech Republic, Denmark, Finland, France, Germany, Hungary, Ireland, Italy, Korea, Mexico, the Netherlands, Norway, Portugal, Sweden, United Kingdom and the United States. An OECD expert team evaluated the policy programs and provisions for children from birth to compulsory school age. Based on the earlier background report of the participating 
countries, the expert review committee published country notes on the observation of issues and solutions, suggestions or recommendations for considerations. The OECD Network is upholding the mandate of the education policy and committee to aid countries in developing effective and efficient policies for education or learning. Through the OECD Network, personal, social, cultural and economic goals are expected to meet. However, the participating countries by far were diverse in context like culture, social, political and economy, hindered in implementing the policies effectively. Thereby, not fulfilling the mandates of OECD Network.

The OECD Network is meeting bi-annually, choosing the theme suiting to policy priorities of network members. The way OECD is involved in promoting quality education and trying to prove equity in all the national boundaries. It is presenting a strategy adopted for the promotion of achieving market advantage through education policy regulations (Rizvi\& Lingard, 2010).The OECD expects that the developing countries improve their education standards and performance to become extremely effective and efficient for economic competitiveness. By focusing equity in education through providing equitable opportunity for all groups of society could involve themselves meaningfully in the children's education process. The OECD therefore, aims to build national and social cohesion to develop them into a global society.

UNICEF ROSA (2015) report shows that South Asia has 584 million children. The most significant part consist of the children under the age of 18 years old and more than a third of the world's children population in South Asia are deprived of essential education, some 42 million children do not go to school at all. It further reveals the gradual progress in girls' education, an increasing gender gap, unsatisfactory quality education and unequal learning opportunities which have become growing concerns globally and for Bhutan too. A piece of evidence need-based to support ECCD as a central focus program for children in Bhutan was made available by the country and other donor countries like the World Bank, UNESCO and Asian Development Bank. However, the first global network that pioneered the establishment of ECCD in Bhutan was Save the Children.

Save the Children developed three models of ECCD for Bhutan; the Community ECCD centers located in both urban and rural areas; the Workplace centers for the children of low wage income employees runs on a costsharing model between the employer and government; Parenting Education Programs as ways of gaining external support from parents' collaboration for the children. However, Save the Children does not pay for any working cost and does not support in daily cost. But it supports the modest funding in programing including policy-making decisions at meso level and it was hoped that Bhutanese children enjoy the benefits from early childhood programs. These supra-national organizations are considered quite influential in tabling programs, guidance and other support to Bhutan. However, lack of resources in human resources, remoteness and financial constraints, poor quality childcare in most of the government-operated childhood care centers hinder achieving social equity. Though people are aware of the purpose of putting early childhood programs across the Bhutanese national boundary, it is becoming increasingly challenging for the government to meet the aspirations and expectations of its people. The children today are offered better facilities, support, and guidance but it is never enough when it comes to quality and equity in early care and education. As change is inevitable and social media secures no boundaries, future remediation might require a varied level of attention and support in early care and education.

Until 2007, the country had to focus on primary and basic education. This was due to the limited budget and lack of sufficient stimulation and interaction that most of the children were falling behind in academics. On that account, the government prioritized the holistic, cognitive, psychomotor, social, and emotional development of the children. Afterwards, the Ministry of Education and the Bhutanese society tried understanding of the benefits of the ECCD. The government's perception of ECCD then started changing with increased influence by an international organization like OECD with support from other international agencies like Save the Children, World Bank and UNICEF. The need for the establishment of ECCD centers in remote pockets of Bhutan was considered urgent. The priority for the setting up of ECCD centers was articulated in the Ministry of 
Education's tenth five-year plan objectives (2008-2013). It also highlighted the desire to promote good practices of early childhood and care between 0-6 years of age by providing a support mechanism.

The Bhutanese government developed a national policy on Early Childhood Care and Education in 2008, including an ECCE curriculum. A curriculum refers to an agreed version of the public about what young people need to learn and who they want to become (Yates \& Grumet, 2011). The stakeholders as the most influential people decided to choose the curriculum possibly based on the Singapore model. This is an evidence of a curriculum pandemic (Vidovich, 2013). As per this model, Pre-primary is de-linked from primary education preventing all children aged 3-6 years out of formal education systems followed by the ECCD operation criteria. One would argue that policy or curriculum borrowing is not bad if relevant and has the potential to improve one's system and get enormous benefits but need to extend a due credit to the policy borrowed. Bhutan's case is it however lacks enough expertise in early childcare development and care. Therefore there are no other ways but to depend on expertise from other countries for guidance and support. However, Bhutanese policymakers are increasingly aware of selecting the best values and not completely copying the policies of other countries. They are getting tricks to design policies in a Bhutanese context. Therefore, it calls for Bhutanese policymakers to be more engaged and critical policy learners than being dependent on the borrowed policies. A critical policy learning has remained a tremendous challenge as Bhutan does not possess much expertise who could design up to date framework based on the factual data collected regularly.

Globalization has been identified as the cause of a policy pandemic. (Vidovich, 2013). As many countries are coming together to take part in the global market, they undergo much change often requiring intervention, regulation and management. Policies then borrowed, could respond to change through their guidance and management practices. It is understandable that in any education reform, education policy has been unsuccessful in improving quality and equity of educational outcomes for two reasons; flawed policies that government focus around structural reforms like governance, finance, workforce, market and accountability, and the other reason is inadequate implementation policies in tension, political priority and policy enactment left to the will of people in the fields (Levin, 2010). Frequently the flawed policies and inadequate implementation of policies can be predicted when policymakers fail to understand the context to which the policy applies.

One such example is operating the standard domain including language and communication consisting of cognitive or intellectual approach towards learning; physical, health and motor development of the children; social and emotional developments suggested for review and adoption of Early Learning and Development Standards (ELDS) of US by the in-country advisors. Bhutanese policymakers are convinced about the benefits that the universal approaches could bring in the society. But Bhutan in many contexts is different to the US so adding moral, spiritual and cultural development domains for country-specific was deemed more relevant to the Bhutanese context.

Given recent reports revealed that ELDS of the US was not in use, instead of hoping to use as inspirational principles as a guiding principles for the development of ECCD and professional development courses (Choden, 2014). A Bhutanese scholar Peday (2013), argues that not having a capacity for ECCD development in Bhutan, had to depend on an external consultant who knows barely about language and culture. Leaders in the ECCD development had come up with a unique approach indicated the "Made in Bhutan" approach.

Through this approach, "The best of the west" benefitting multicultural values is incorporated with focus on local knowledge, values, and practices, which are in line with Gross National Happiness (GNH) philosophies. Bhutan's ECCD policy, therefore, is being careful not to be engaged completely in policy pandemic which Vidovich (2015) mentions in her definition of policy pandemic on 4th March as, "borrowing, sweeping across continents and countries with completely distinctive historical, cultural, political and economic traditions and circumstances." However, Bhutan is also being careful about the selection of suitable practices of the other countries and more importantly, inculcating cultural traditions, Indigenous Knowledge and supporting children's pride in which they are as Bhutanese citizens for sustainability. The Bhutanese government is ensuring that early 
learning opportunities for early children can reap the fruits at later age. Taylor (2011) mentions the impact of quality early learning experience in ensuring personal well-being, social and academic achievements in diverse communities. Further, he argues how crucial the government's interest is in supporting development and learning with the growth of knowledge will essentially impact the children.

The ECCD policy of Bhutan is centrally regulated through its devolution and accountability practices. Vidovich's devolution and accountability practices dated 18th, March (2015) claim that devolution is the increasing local autonomy and accountability is the increasing control from the center. In this line, the Gross National Happiness Commission and National Education Department were accountable for framing policy guidelines and reviews basically to ensure the effective operation of ECCD in the country both at national and local levels. The government and other stakeholder groups are devolved with ECCD operations. For example, at a national level, the government outsources funding from the developmental partners and at local levels, NGOs like Tarayana Foundation, Loden Foundation, and local contributions are made available for early childcare access and quality learning. The Royal Education Council is the responsible body for research and documentation on ECCD. The roles of stakeholders in the development of Bhutan's ECCD policy reveal evidence of moving away from bureaucracy towards cooperative management, proven to sustain enormous growth in education. One such program is the parenting program for ECCD children.

\section{Discussion 1}

\section{Policy Text Production}

The stakeholders of the Early Childhood Care and Development (ECCD) under the Ministry of Education consist of representatives from the government and non-government. They are participating and collaborating by introducing the National Policy on Early Child Care and Development in Bhutan since 2008. Ever since, the National policy is directing towards providing quality early childhood care and development services to children from birth to eight years. In addition, an essential strategy for developing human resources, "to nurture future community of Bhutanese to become responsible and productive members of society" (RGoB, 2011). This is in agreement with what Wise, Ungerer \& Sanson(2002) believe about the early years of a child's life as widely recognized, critical to their later development. Through early childhood programs, children are expected to capture early stimulation, guidance and a range of developmental activities and opportunities necessary for addressing dimensions: care and education as a part of development (UNESCO, 2007).

Bhutan has almost $30 \%$ of the young population under the age of ten as per Population and Housing Census of Bhutan (PHCB, 2005). Most of them will start their schools without the benefits of services fostering general wellbeing and enhanced school readiness. Therefore, quality and equity gaps have been viewed as the most challenging issues and expected to widen if appropriate interventions are not put in place. Education without compromise report (2008) illustrates a considerable number of repetitions of grades and low pattern of test scores in primary schools persistently. And this is an indication that the government should prioritize the formulation of provisions for quality ECCD programs and services in the country through realistic policy interventions. There are considerable benefits for society as a whole, individuals and families concerned when the public begins investing in quality childcare and education services, in particular for the children from lowincome families(Wise, Ungerer \& Sanson et al. 2002). They argue that the highest performing education systems are marked by a combination of equity with quality. Their arguments provide opportunities for achieving good quality education and recommendation for children to succeed in schooling. They also looked into policies at school systems to promote equity and quality. A considerable significances of the support system for leveraging opportunities for disadvantaged students were found crucial for narrowing the gaps. However more than anything in Bhutan, an active field participation and collaboration from stakeholders are significant for achieving anything meaningfully. Capacity building of the care givers and more funding in the remote schools are recognized critical to gain benefits from participating in the world. 
Bhutan is an agrarian country with a low income index. The country development goals and policy demand investment in childcare development. Because of investing in ECCD development, it is expected that lives of the rural children improve. These ideologies are enshrined in the scope of ECCD policy. It explains how children's thinking ability leads to creativity and innovation; establishing relationships for improved interactions with others. The quality care services for health and nutrition and opportunities for holistic care for success at schools, healthy development for future workforce and potential to prosper economically are some guiding principles for early care and development. Much of the roles that the stakeholder need to play are also mentioned. The policy guideline states that they are their roles are the most influential aspects of ensuring quality and equity in education. A significant support procedure for these disadvantaged children are also highlighted. This is all to make rural people equally competent like their counterparts in urban areas. Their competency is expected to improve global markets. Yates (2011) claim that the purpose of school is not about schooling but about participating in the world.

The ECCD policy framework of Bhutan aims to give the best start in life, including children with specific needs so that they could attain to quality early childcare and enhance equity in educational endeavor. It promotes and strengthens comprehensive, cost-effective and sustainable Early Childcare and Development programs through private, public and community participation. It also promotes the roles of parents, caregivers and the community in holistic development of the children. An integration of early childhood care and development services into the existing family institutions and communities is intended to promote equity and quality too. The provision of adequate resources for supporting early childhood care and development programs and services are also considerably stated. The enticing views on school readiness through physical wellbeing and motor development, social and emotional development, approaches to learning, language development, cognition and general knowledge are recognized.

The strategies are drawn by advocating and mobilizing childcare practices and promoting quality services and the establishing of public, private and community-based childhood care and development centers. The policy also covers facilitating and promoting "operational guidelines for ECCD centers" to make sure that minimum standards in all ECCD centers achieved. It also ensures that the provision of quality early childcare and development programs through National Early Learning and Development Standards (NELDS). It is a guiding document for the development of the curriculum, parenting education and training modules in all Early Childhood care and development centers. The ECCD services provided by various agencies shall be approved, monitored and regulated by the ministry of education for ensuring the quality and contextual relevance is met. However, the point lies in developing stakeholder roles, coordinating and collaborating their tasks.

Taylor et al. (2013) \& Mc Gaw(2008) have shown how important high-quality early childhood education and care are in preparing children for their later educational success. Mc Gaw's article "How Good is Australian School Education?" shows that Australian schools possess excellent quality and low equity. His findings aimed to focus on improving the equity of socially disadvantaged children. The equity issue is similar to Bhutan. The equity focus in Bhutan is generalized evidently from the policy discourse as levelling private, public and community ECCD centers as same for all three which otherwise needed numerous interventions. The policy does not contain any significant programs; Priority statements or extra services like an extra provision to fund or allowances for retaining quality caregivers in remote settings to gain equity. This is one of the reasons why socially disadvantaged children from remote places are constantly unable to access to quality care and education.

Unlike Australian caregivers with degree certificates and additional certificates like accredited qualification in first aid, health and nutrition, and childcare, Bhutan's caregivers do not possess skills to meet the growing demands of the country. The government could explore possibilities of establishing more early leaning institutions and ECCD centers, not just highlighting in the policy but also enacting through reforms and mechanisms. As quality of caregivers impacts the quality learning of the disadvantaged children, care givers' 
status and qualification could assist in establishing conditions for the purposeful early learning and care. Levin (2010) states that teachers cannot force students to learn; they can generate conditions in the form of support and encouragement that require learning more likely to happen.

\section{Discussion 2}

\section{Practices and Effects}

A Community Early Learning Centre (name confidential) is one of the government-operated early care centers in rural Bhutan. The ECCD center has just one room classroom that can accommodate about 20- 30 children. The center does not contain much space for children to explore with two facilitators who manage the business of caregiving. On top, learning resources are inadequate. Children come to this center as early as eight in the morning and devote their time there till noon. The caregivers teach the curriculum highly centralized containing urban orientations, which is unfamiliar to these children. Furthermore, the medium of instruction is English making it difficult to understand rhyme and phonology. For most of the children in urban or western parts of Bhutan, it is their secondary language. For the children in this village, it is their third or fourth language. Therefore, their low level understanding challenges them, so the facilitators habitually employ their local language for communication. Children also come from remote places that become difficult for education officials to visit and monitor the programs. On the contrary, children in urban early learning centers seem to benefit and gain popularity there due to their unlimited access. The parents too are more positive to direct their children even to the privately owned early learning centers in urban areas because they understand the urban choices and orientation. The rural parents due to social and economic factors fail to equate with the urban parents. Therefore, widening more gaps instead of reducing social disparity.

Though ECCD policy text is produced involving many stakeholders with devolved practices and accountability, The ECCD framework requires a much explicit approach. According to Dawson Street Child Care Cooperation's (DSCCC, 2014) Inclusion and Equity Policy, inclusion refers to ensuring all children's participation and feelings of belonging. It equally refers to the right that every child claims a part of a childcare community, joins in childcare activities and has a voice that happens to them. DSCCC supports that the lone child and their needs are to be valued and respected. It affirms the need for programs and practices such as adopting a flexible approach to education and care making appropriate expectations for each child. The need for assisting staff development with relevant skills and knowledge necessary with working with all children and their families, supporting staff and making contact with specialist services are also stated. All above are generalized statements to be carried out across the country. In reality, every individual or community's needs are different so call for an explicit approach regarding clear on training and monitoring procedure etc. It is significant for the Bhutanese government to reflect and introduce explicit and exclusive policy statements for children in the remote areas for their rights ought to be valued.

Evaluation strategy of ECCD programs must be strictly executed for better accountability practice not just enshrined in policy text. Choden (2014) reports that early childcare programs have been unmonitored so far and hoping to be monitored in 2016 which it did. As the ECCD policy in Bhutan has been enacted just a couple of years, the ministry of education is not in the position to monitor the stakeholders' collaborations besides monitoring of ECCD centers only. The ECCD monitoring reports constantly indicate a requirement in the improvement of areas like training, collaborations, and support from and within the stakeholders. The lack of cross service agreement and explicitness on what needs to be valued and how to monitor learning and educational progress becomes a challenge to ascertain the relative impact of service provision on child development (Elliott, 2006).

The ECCD policy of Bhutan is expected to benefit disadvantaged children of remote corners but hasn't proven much success in achieving equity and social justice. This is agrees to the reasons that Braun et al. (2011) claim 
about enacting policies depending on school-specific context. According to the policy relevancy model of four dimensions: situational contexts containing school histories, settings and enrolment; professional contexts like teacher commitment, experiences and policy management; material contexts like staff, budget, technology and infrastructure; external contexts like legal compliances, locality support and inspections can help or hinder an enactment of policy. The ECCD context in rural Bhutan is diverse in all the contexts therefore, hindering policy enactment there. Taking four dimension models of Braun et al. (2011), the government could solve equity issues if rural children are better supported and given priority in childhood care and education reforms which many rural ECCD centers now critically face.

As learning is a two way process, the modern curriculum demands students to be effective problem solvers, highly creative and communicative, high order thinkers, and intercultural competent and collaborative workers and teachers and caregivers to be competitive so that children gain ground in these necessary key competences. The caregivers in rural Bhutan lack the necessary skills and knowledge owing to low qualification and inadequate education so the ECCD curriculum cannot be implemented adequately. On top, the low literate parents, inadequate budget, less resources, and inadequate infrastructure remain the primary reasons for an inefficient enactment of the policy. Therefore, the framework needs an explicit approach and exclusive policy statements with reasonable grounds for enactment. As well as better support mechanism for funding the programs. The collaborative networks of stakeholders require proper guideline with check and balance strategies.

\section{Conclusion}

The people's mobility increased because of improved roads, transport and communication. Along with it, the circulation of ideas, images and ideologies have also become rampant across the national space. These active circulations of transnational policy undoubtedly contain fundamental ideas admirably expressed in the form of modern contested conventions and commitment towards achieving human rights, democratic elections, social benefits, and educational opportunities. Behind this idea circulation is making children extremely competitive and children have to literally compete against time and space. However, the mobility of the rural people of Bhutan has not changed completely. The social imaginary of their children remains like some three or four decades back, being unable to connect properly with the world and this leaves them socially unjustified and unequal. The social imaginary of how people must positively identify themselves and be able to positively relate to the modern world matters for such social imaginary creation (Rizvi \& Lingard, 2010). Conversely, a radical shift in economic activities has resulted in increased workers' social insecurity. The Bhutanese government must recommend priority policy interventions suitable for the rural children to prepare them to stabilize and be able to adequately relate to the idea.

Stakeholders are the most influential people in policy implementation. The most influential stakeholders in urban ECCD centers in common are concerned parents who are more educated and able to recognize its possible benefits. They tend to seize better opportunities from the private and cooperate early learning and care centers that are better resourced with better accountability. This is evident from the standard and learning outcome of urban early active learning at the education centers. The children from urban ECCD centers are found more outspoken, confident and naturally have a high literacy level compared to the children from remote places. Therefore, the parents in the rural must be empowered and made literate to recognize the benefits of ECCD programs and assist their children in achieving quality early child support. Plus, the government must come up with engaged policy review and evaluation to bring in an explicit and inclusive approach with rural specified statements to achieve quality and equity.

The fact that the government is coming up with parenting programs, it has come to be an effective way of persistently advocating the values of childcare and development. Through these programs, parents are increasingly made aware of the fundamental importance of early childhood development and care. To conduct such programs, depend upon expertise, financial resources and time. They are acute in supply posing threat to 
their sustainability and consistency. Besides, policy relevancy needs be studied as it expects policy statements at varying levels like macro, meso and micro levels for better network and outcome of the policy enactment. To a great degree, follow up, and effective strategies for continuous improvement of the ECCD programs needs be reasonably considered.

Through the development of ECCD policy documents and enactment, the government of Bhutan aspires to meaningfully improve the social imaginary of Bhutanese children in this globalized world. However, policy enactment typically depends on the relevancy of the contexts. In the rural context Firstly, the necessary resources are scarce, and choices and affordability are limited. Secondly, parents' voices are weak due to limited exposure and low-level literacy. Lastly and the most essential point is the underqualified care givers. Therefore, policy statements must consider exclusive and specific statements about qualification and trainings in quality and care so that their social imaginary progressively improves with time, adequate support and effective guidelines. In this manner, the social and economic differences would be narrowed reasonably achieving quality and equity in ECCD across the social boundaries of Bhutan.

ECCD policy and Education study has enormous scope as it gained attention just a decade ago. The department is headed by just a couple of people in the head quarter. Because of this, ECCD roles are widely distributed among stakeholders such ministry of education, health, communities, parents etc. They in the fields do not undertake the responsibility seriously as it is their secondary job. There aren't any case study reports or research based on data and it lacks critical supervision and necessary support .People may claim that they are doing the job but just doing is inadequate .Overall, significant research topics for deep examinations are available for future researchers. Like any research has limitation, my investigation too may not have covered all the areas but might have definitely spark up. Down the line, significant topics on ECCD could be explored for investigation.

\section{References}

Ball, S. J. (1993). Education policy, power relations, and teachers' work, British Journal Of Educational Studies, 41(2), pp.106-121, DOI: 10.1080/00071005.1993.9973954

Ball, S., J. (1994). Education reform: a critical and post-structural approach, Open University Press, Buckingham [England]; Philadelphia.

Ball, S., J.(2006).Education policy and social class: the selected works of StephenJ.Ball, Oxon [England]; Rutledge.

Ball, S., J.(2007). Education p/c: understanding private sector participation in public sector educational, Oxon[England]; Rutledge.

Ball, S., J.( 2008).The education debate, Bristol [England], The Policy Press.

Blackstone, A.(2015).Principals of Sociology Inquiry: Qualitative and Quantitative Methods Catalog. Flatworld knowledge. com. Date of access: 10/8/2018.

Braun, A., et al.( 2011). Taking context seriously: towards explaining policy enactments in the secondary school, Discourse: Studies in the Cultural Politics ofEducation, 32(4), pp. 585-596, DOI: 10.1080/01596306.2011.601555.

Choden, S.(2014).Serving Childcare Needs, Kuenselonline, 6th August. Date of access:12 //8/2018.

Cobbold, T.(2011).Fighting for Equity in Education, Save our School.com .au, Date of access;11/8/2018.

Connell, R.,et al.(2013). Education Change and Society, Oxford [England], Oxford University Press. Dawson Street Child Care Co-operation (DSCCC).2014, Inclusion and Equity Policy, 26 March, Dawsonstreetcc.org.au. Date of access: 15/8/2018.

Dem, K. ( 2017 a: 2018b \&2019c). Quality Monitoring Tool for ECCD (QMTEC) Report, Ministry of Education, Bhutan.

Elliott, A.(2006).Early childhood education. Pathways to quality and equity for children, AERReview 50, Camberwell, Victoria [Australia], Australian Council for Educational Research. 
Gaw, B. (2008). How good is Australian school education?Education, Science and Public Policy: Ideas for an Education Revolution, Melbourne [Australia], Melbourne University Press, pp. 53 - 77.

Ghosal, D.( 2012).Early Childhood Care and Development: Setting the Stage for lifelong Development. The World Bank, IBRD: IDA.

Levin, B.(2010,).Government and education reforms: some lessons from the past 50years. Journal of Education Policy, 25(6), pp. 739-747.

Ministry of Education.(2008).Education Without Compromise: Sector Review Commission, Bhutan.

Ministry of Education.(2008). National Policy on Early Childhood Care and Development, Royal Government of Bhutan.

Organization for Economic Co-operation and Development (OECD).(2015).Better. Policies for better lives: Early Childhood Education and Care, Oecd.org.

Ozga, J.(1987). Studying education through the lives of policymakers: An attempt to close the micro-macro gap, pp. 138-150. In S. Walker \& L. Barton (Eds.), Changing Policies: Changing Teachers, Milton Keynes, Open University Press.

Ozga, J.( 2000).Policy research in educational settings: Contested terrain, Open University Press, Philadelphia.

Rawls, J.(1921).Theory of Justice, Library of Congress Cataloging-in PublicationData.US.

Rizvi, Fazal., et al.(2010). Perspectives on Globalization, Globalizing Education policy, London, Rutledge: pp. $22-43$.

Sharpa, S.(2013). Social policy: The issues, Getting Early Childhood Development Right, UNICEF, Bhutan.

Sheridan, M et al.(2012). The Impact of Social Disparity on Prefrontal Function in Childhood PLoSOne,7 (4):e35744.doi: 10.1371/journal.pone. 0035744. Epub.

Tayler, C., et al.(2013). The quality of early childhood education and care services in Australia online].Australasian Journal of Early Childhood,38(2) Jun2013:1321. Availability: ISSN: 1836-9391. Date of access: 19/4/18.

United Nations International Children's Emergency Fund (UNICEF) ROSA.(2015). The children-The Children,www.unicef.org/rosa/children Html, Date of access: 8/10/2015.

Vidovich, L.( 2015). Introduction: Education policies \& practices, The University of Western Australia, class notes, 25 February.

Vidovich, L.(2015).Global policy trends-focus on quality and equity, The University of Western Australia, class notes, 11 March.

Vidovich, L.( 2015).Globalization \& the Knowledge economy/society, The University of Western Australia, class notes, 4 April.

Vidovich, L.( 2013).Policy research in higher education: Theories and methods for globalizing times.Ind.Huisman\&Tights(Eds.), Theory and method in higher education research, international perspectives on higher education research,9(21)-C39.Emerald Group Publishing Ltd.

Wangchuck, C .,et al.(2013).The Status of Early Childhood Care and Development in Bhutan: An internal report for ECCD situational study, Bhutan.

Wise, S., Ungerer, J. and Sanson, A.(2002). Childcare Policy to Promote Child Wellbeing.Australian Economic Review, 35, pp. 180-187. DOI: 10.1111/1467-8462.00234.

Yates, L., \& Grumet, M.(2011). World Yearbook of Education 2011: Curriculum in todays World: Configuring Knowledge, Identities, Work, and Politics (World Yearbook of Education). Hoboken, Taylor, and Francis. 